\title{
OPPORTUNITIES FOR REAL-TIME DIGITAL REFERENCE SERVICE
}

Matthew R. Marsteller* and Jackie Schmitt-Marsteller**

*Physics and Math Librarian, Carnegie Mellon University, Engineering \& Science Library, Room 4400 Wean Hall, Pittsburgh, PA 15213-3890,

e-mail: matthewm@andrew.cmu.edu

**Director, South Fayette Township Library, 515 Millers Run Road, Morgan, PA 15064, e-mail: schmittmarsj@eiNetwork.Net 


\begin{abstract}
This article explores the opportunities that real-time digital reference service can offer to a variety of library settings from the independent public library to the large multicampus university or the multi-national corporation. There are many occasions when a real-time digital reference service will be the optimal solution for a portion of a library's reference service. The authors' goal is to offer our original ideas, and examples from the literature, that will stimulate thought about real-time digital reference services that could be offered by your libraries. The numerous ideas and examples should provide the reader with workable methods for extending the reach of reference service to under-served populations.
\end{abstract}

\title{
KEYWORDS
}

Real-time; synchronous; digital; virtual; chat; electronic; live; reference; kiosks; public libraries; academic libraries; special libraries; school libraries; information and referral 


\section{INTRODUCTION}

The literature and the listservs are flooded with information about real-time digital reference service. Discussion of the topic has increased during the last five years, but the idea is not particularly new. On the DIG_REF listserv, veteran real-time digital reference providers who worked for a company called Telebase discussed the birth of

their real-time digital reference product that occurred nearly twenty years ago. ${ }^{1}$ Because of the current glut of information, the authors felt that a focus on practical applications was needed.

There have been attempts to dismiss the need for real-time digital reference. Lankes and Shostack conducted a study of an e-mail based Ask-A service that only focused on the satisfaction of its users, with no attempt made to gage the desire for a real- 
time service. Their argument was more of a defense of e-mail reference than a refutation of any need for real-time digital reference. ${ }^{2}$ The authors of this paper agree with Lankes and Shostack that e-mail reference has its place in library reference services, but do not propose that the utility of e-mail reference is a reason not to pursue real-time digital reference. An op-ed article by McKinzie and Lauer warned that real-time digital reference was overrated and fraught with administrative difficulties, another opinion that the authors of this paper disagree with. ${ }^{3}$ One argument against real-time digital reference service that McKinzie and Lauer make is that librarians “...model habits of information trolling and gathering"4 and "[t]his modeling is almost impossible to develop over fiber optics." However, it would seem that any sound demonstration of real-time digital reference software that offers cobrowsing would immediately refute this. Page pushing, interspersed with search strategy suggestions, is a step down from cobrowsing (also referred to as escorting) on the scale of personal interaction, but it can also effectively model the librarian's search behavior and thought processes. In a post to the DIG_REF listserv, Nancy O'Neill indicated that she used the page push feature of 24/7 Reference - a feature rich tool for real-time digital reference - more than 60 percent of the time. ${ }^{6}$

The main argument for the provision of real-time digital reference is to have the librarian available to the patron at their time of need. In 1999, Tennant stated: "The digital library is a lonely place."7 Some people may prefer the privacy and loneliness of independently using electronic resources, while others find it desirable to have a level of mediated help that doesn't include face-to-face or telephone interaction. Real-time digital reference enables the patron to have immediate acknowledgment and assistance 
instead of being isolated in the complex electronic resource world or facing the unknown timeline and reliability of sending questions via e-mail. The provision of real-time digital reference service has made the Internet a far less lonely place. However, real-time digital reference service can also make the Internet a place where many people will find their highest level of personal comfort with the library. Tenopir states "Having multiple options for communication means being able to help patrons more appropriately." Libraries, individually and in collaboration, are assembling vast digital collections for their patrons' use. Are we to ignore the users of these collections, or should we insure that we are there to help them effectively utilize these expensive resources? The answer would appear to be obvious.

This article will review opportunities for real-time digital reference where this medium is the optimal choice for provision of reference service. The review is structured by library setting, a choice made only to lend form to the article and not meant to dissuade collaboration by different types of libraries. Indeed, there are already several multi-type collaborative efforts that serve as shining examples. The readers are cautioned not to overlook the possibility that an idea expressed in one setting may be applicable in another. The authors have not focused on the details of starting up real-time digital reference services. The goal is to offer our original ideas, and examples from the literature, that will stimulate thought about real-time digital reference services that could be offered by your libraries. 


\section{OPPORTUNITIES IN THE PUBLIC LIBRARY SETTING}

Everything today is about speed and convenience, for better or for worse. People are overloaded - overloaded with responsibilities, technology, visual and auditory stimulation, brands - there is so much of everything that it is hard to sort it all out. It is only when something stands far above the maddening crowd that its superiority is achieved. Librarians must face the fact that this is the society in which libraries must function. Each library must carve a niche for itself based upon the needs of its users and what strengths it has developed to fulfill those needs. Call it continuous quality improvement, reinventing one's self, commitment to change, or any other organizationally savvy phrase. Whatever it is called, the fact remains that money-and people's attention—are not limitless resources, and the competition for both is ferocious. Libraries must be ferocious competitors with other service providers, and with each other, in order to remain relevant and worthy of continued funding and patronage. Libraries that provide real-time digital reference services should remain competitive in today's information marketplace.

Whether librarians like it or not, the Web is now a huge part of reference service. Many people think that they will be able to find all of the answers and information they need on the Web. How sad for them, but it represents a tremendous opportunity for librarians to make sure that our patrons are using reputable sources, and are instructed in how to use them correctly and effectively. A reference librarian's job is not as different today as some people would think or lead the profession to believe. Put simply, the Web is just one gargantuan library of excellent, marginal, and disreputable resources, and 
librarians must help people determine which resources to use and how to use them.

Librarians do this on a regular basis within the library building. It is our non-users that we must concern ourselves with in terms of how we best reach them and get them to use

library services. Fortunately, real-time digital reference can help libraries reach users and non-users regardless of where they are located or when they are in need.

A must-read for library professionals interested in the future of libraries and their use of technological innovation for service provision is the proceedings of 3M Library System's 1998 summit "Vision 2008." For librarians considering the implementation of real-time digital reference, there are great lessons to be learned from the results of the summit. Making this service available and keeping its costs down allows the library to be a competitive step ahead of fee-based information services, which fits right into a "best future scenario." Deciding whom the end users will be, and analysis of those users, results in the implementation of only the services that are needed. Again, this fits well into the best future scenario of market analysis and keeping costs down for the user. Finally, the provision of real-time digital reference remotely and at varying times, as well as the training of users via page pushing and cobrowsing, also conforms to the best future scenario. $^{9}$

\section{Generic services}

Small to medium sized public library directors and reference staffs need not believe that offering real-time digital reference service in their libraries is impossible. At the 2002 Virtual Reference Desk (VRD) Conference, Sathan delivered a presentation 
about Memorial Hall Library's 24/7 reference project. Although the authors would hesitate to call it a small library (thirty public Internet terminals were available), Memorial Hall Library's collaborative real-time digital reference project is definitely of interest to public librarians wondering if it is possible to provide $24 / 7$ reference in their libraries..$^{10}$

"Sunday Night Live! - An Experiment in Real Time Reference Chat - On a Shoestring Budget," describes the year 2000 real-time digital reference project of the Suffolk County New York Library System. The system chose Ticketsmith for its log on and statistical tracking capabilities, and HumanClick for its chat and page-pushing capabilities. Suffolk County had little problem recruiting librarians for the project because the project was perceived as new and exciting, and the real-time digital reference librarian was provided with a laptop that had special connectivity to the library's server. One reason for establishing the service was the system's purchase of an extensive collection of digital products, many of which had diverse search interfaces and features that might overwhelm the patron. It was felt that real-time digital reference would help to insure an adequate and increasing level of patron use of these expensive resources. The library system found that the reliability and functionality of the software were vital to the success of the service. This included the ease of patron log on, the lack of patron requirements to have special software or to complete downloads, and the ability for librarians to use automated responses. The librarians found it difficult to handle multiple sessions simultaneously and the addition of a "Leave a Message" feature resulted in an increased number of e-mail questions which necessitated a daily check and resolution of e-mail. Many case studies of real-time digital reference indicate that libraries experience 
a marked increase in e-mail questions. As a result of their Sunday night experiment, Suffolk County planned to extend the service to other evenings and to increase publicity, committed to the idea that the service would become as normal for libraries to provide as telephone reference. $^{11}$

Another project worthy of attention is the LSTA-funded Washington Statewide Virtual Reference Project. Although the project's definition of Virtual Reference Service includes email and online forms along with real-time digital reference, it's focus on the development of best practices, methods, standards, and cost/benefit models should have wide and useful application to libraries considering implementation of real-time digital reference services. $^{12}$

One opportunity that should never be overlooked is the chance to market library services. For the time being, real-time digital reference enjoys the status of being "cool." The provision of such a service may act to break down non-users' misperceptions of the library. The mere existence of a library Web site that describes it may enlighten the Internet savvy non-user who has no knowledge of the library's services and resources (or perhaps even its existence).

Geographical barriers have long been a challenge for library services. Real-time digital reference in conjunction with digital resources can be extremely important to segments of the population that have no library located in or near their community, such as children in rural areas and people with limited transportation options. Libraries in large cities also find it difficult to serve children when busy streets are between the child and the library, or when the child is not allowed to travel alone. 
Because the authors are not children's specialists, examples of real-time digital reference services such as homework help services are not included in this article. If the reader has identified a need for such services - and it is safe to say that the need exists in many public libraries - a significant amount of library and non-library literature is available.

Low use of libraries because of inadequate physical facilities such as minimal seating, lack of a quiet study area, or bad lighting can be partially overcome by building digital collections and relying on the patrons to supply the ambiance for their library experience. Building renovations can also result in a situation where physical facilities may be unavailable. Providing the local community with access to the library's digital resources and real-time digital reference service during renovation projects may help to insure continued state funding even though the building is closed. Offering after hours real-time digital reference services will serve patrons who are unable to use the library during normal operating hours or whose information needs emerge at inconvenient times.

\section{Kiosks}

Some public libraries have placed ATM-like kiosks in remote locations from library buildings in order to connect with under-served populations. In 2001, the Platteville Public Library (CO) spent $\$ 50,000$ on an e-Branch Library kiosk manufactured by Public Information Kiosk, Inc. ${ }^{13}$ Although the kiosks are expensive, they are less expensive than building branch libraries, staffing those libraries, and paying overhead. The kiosks, which can be found in such locations as schools, grocery stores, 
and malls, provide patrons with access to libraries' web sites and card catalogs, enabling materials to be reserved and reference questions to be asked. The machines have the capability to scan and read library cards, send faxes, take money, and enable access to email and the Internet. The machines can also be adapted to serve the needs of the physically disabled. PIK assesses an annual fee to the libraries for the cost of maintenance and web site services. In 2002, PIK and LSSI entered into a partnership to offer LSSI's "Virtual Reference Services" on PIK's e-Branch Library kiosks. The possibilities of using kiosks to provide real-time digital reference, particularly to underserved segments of the population, are numerous and exciting to public librarians. Mathies states,

"One of the great benefits of the e-Branch Library kiosks is that they help level the playing field between the 'haves' and the 'have-nots' by making many of the library's electronic services available to those who don't own a computer or an Internet connection. This is of particular concern to libraries running virtual reference services, because - up until now - these new and innovative services have largely been limited to those who had the computers and technology to access them. But not any longer. Now any member of your community can access live library reference services (as well as your catalog, databases, and other electronic services) 24 hours a day, 7 days a week, from any eBranch Library kiosk."

Mathies goes on to describe how the kiosk and the interaction works:

"Patrons simply touch a button on the eBranch Library screen to connect with a librarian any time of the day or night. The librarian opens up a shared browser on the kiosk which she can use to send Web pages to the patron, 'escort the patron' through searches on the library catalog, databases, or statewide information resources, and the librarian can even send photocopies or scanned images from books, journals and print resources to the patron - all live and real time. The librarian and patron may communicate via 'chat' or simply by talking over the phone that's built into the kiosk. Once the interaction is completed, the patron is emailed or faxed a complete transcript of the session for future reference."

The "Virtual Reference Services" feature of the kiosk can be set up so that services are totally provided by LSSI, or LSSI is used to cover some hours of the library's real-time 
digital reference service, or LSSI software may be purchased and used by the subscribing library to provide the service via the kiosk. ${ }^{14}$

Another example of the use of library kiosks is the Millennium Library of Cerritos, California. The mission of this 2002 project, designed through collaboration by Hewlett-Packard and the city's IT and building contractor staffs, was “to create an elearning experience for kids and adult ... beyond just providing Internet access to patrons through kiosks...create a library that everyone would enjoy as a gathering place for the community for a shared learning experience." ${ }^{\prime 15}$ The technologically-rich kiosk provides the ability to interact via real-time streaming video, enabling such uses as real-time digital reference via video-conferencing and provision of informational programs in realtime to remote locations.

Other public libraries involved in the use of kiosks for providing real-time digital reference services include the State Library of Hawaii Public Library System, ${ }^{16}$ the Brevard County, FL Library System, ${ }^{17}$ and the Connect IT Omaha project of the Omaha Public Library, NE. The Connect IT Omaha 2002 Community Technology Fund Grant Application could be used by other libraries as a model for similar kiosk-related projects. ${ }^{18}$

It is also important to note that kiosks provide a partial solution to the problem that some real-time digital reference software products have with non-Microsoft operating systems. At least libraries will know that all patrons, regardless of the type of computer they own and the operating system used, will be able to reach them via the kiosks. 


\section{Information and Referral}

Information and referral services are traditionally provided by public library reference departments to connect patrons with other community information and service providers. The advent of real-time digital reference services provides a host of opportunities for enhancements to this important aspect of public library service.

A librarian in an urban setting whose library allows telephone use by, and on behalf of, patrons may have occasionally made phone calls for people needing information on social services such as food banks and homeless shelters. Making this telephone call or allowing the patron to use the telephone is not typically within the realm of library services. Tying up the library's telephone line, allowing the patron to access staff areas, the lack of privacy afforded to the patron who is using the library's telephone, and the potential embarrassment caused when the telephone call is made by a staff member on the patron's behalf, are all issues of concern. It is possible that real-time digital reference technologies can be utilized for these and other types of information and referral while adequately addressing the concerns expressed above. For example, free or inexpensive chat software - or already-existing Internet chat rooms - can be used by service providers to make themselves available to library patrons and community members in need. Patrons may access these providers through the library's computers, home computers, or kiosks. Thus, information and referral can be provided by community and government agencies via real-time digital reference technologies hosted by the public library, without the need for telephone access. Taking this idea a step further, let us assume that the patron in need of a social service cannot type, or cannot 
read. With the addition of relatively inexpensive software and peripherals, voice communication using voice-over Internet protocol (VoIP) technology can be provided. The possibilities of using this medium for information and referral are numerous when considering the ability to reach and easily interact with people who cannot type, read, or for some other reason cannot use chat. Public libraries will often have the Internet connectivity capable of supporting VoIP.

\section{Citizen Information and Participation Services}

Public libraries may want to consider using real-time digital reference technology to host a citizen information and participation service for local government in order to enhance citizen involvement and strengthen neighborhood initiatives. An example of services that public libraries could become involved with are the LUV (Linking Up Villages) initiatives of Dorchester, MA and Newark, NJ. Low-cost, graphics-capable software called MUSIC (Multi-User Sessions in Community) is used to provide the following capabilities to residents: Access information about community activities and services; Organize neighborhood coalitions; Offer input and express concerns to local government officials; Create and access community databases; Post help wanted ads; Apply for jobs; Participate in online discussion groups; and Conduct real-time informational chats. The system is easy to use and the technology is inexpensive. ${ }^{19}$

Another interesting citizen information and participation service that libraries could model their initiatives after is the Blacksburg (VA) Electronic Village (BEV). In 1996, Andrea Kavanaugh envisioned the service including "broader use of chat services 
... to support carefully focused and scheduled online meetings to discuss specific issues and topics," and "extensive, broad-based training to ensure citizens have the skills and expertise needed to effectively use the new channels for civic communication." ${ }^{20}$ A forward-thinking public library might propose to collaborate with local government to host the village and/or provide training to the public in how to use such a resource. Not only would the library be using a proactive and creative approach to fulfill its educational and informational missions, but collaborating with local government might have a positive effect on government officials' perception of, and financial support of, the public library.

\section{Real-time digital reference services for senior citizens}

Results of a survey of one hundred residents of Warrensburg, MO ages 65 and older found: 70 percent of survey respondents considered the computer to be a companion; More than 50 percent participated in electronic gatherings such as chatrooms, and; 94 percent expressed a desire to learn new technology. ${ }^{21}$ Although these numbers cannot be said to be representative of a larger group, the authors of this article have observed that the willingness of senior citizens to use computers and learn new technologies has grown as the popularity of E-mail and the Web has grown. Also, many of today's retirees participated in the advent of the computer revolution. This has opened up great new potential for library services to senior citizens, and the old notion of the "library without walls" is taking on an exciting new meaning. Homebound services, which traditionally included only the delivery of books and other library materials, can 
now be enhanced with any real-time digital reference service that has been identified as needed or desired.

An interesting example of a public library's real-time digital service to senior citizens is the Palchat service of Acacia Ridge Community Library (Brisbane, Queensland, Australia). Seniors use the service primarily to communicate with friends and family, as well as make and maintain friendships with people around the world. The library provides weekly Palchat lessons and even provides microphones so that seniors who can't or don't want to use the keyboard can still chat. ${ }^{22}$

Let's take this idea a step further and consider outreach services that public libraries provide to nursing homes, assisted living centers, residences and senior centers. The authors have provided library services to seniors and have seen first-hand the benefit that these services, particularly ones that include a reader's advisory interaction or other intellectual stimulation, can provide. It's somewhat surprising how seniors with mild Alzheimer's or dementia may forget many details of daily life, but remember precisely what day and time the monthly library visit is. Popular and professional literature has suggested that interpersonal interaction and intellectual stimulation are important to well being as one grows older. Add to this the growing interest among senior citizens in new technologies. The result is a great opportunity for public libraries to enhance their outreach services to seniors through the use of real-time digital technologies.

A public library might consider collaborating with a group of nursing homes, assisted living centers, residences and senior centers - or with a senior service provider like a county Agency on Aging - to place computers in locations where seniors live and gather. The library can set up chat rooms on health, current events, books or whatever is 
of interest to its seniors. A real-time digital reference service can be incorporated into the project, enabling seniors to get immediate access to information and receive help in using the library's resources. The library can also offer training sessions on location.

\section{Real-time digital reference service for the disabled}

Australian public libraries are highly involved with the provision of online services to people with disabilities. A literature review by Monash University written in conjunction with the Commonwealth's AccessAbility project "Online Services for People with Disabilities in Australian Public Libraries" provides some very important information that justifies, and demands, public library efforts in providing digital services to this audience. The report keenly states,

"As online technologies and information services become more and more prevalent and an integral part of everyday life, it is vital that people with disabilities can participate equitably in the information economy. Online services have particular benefits and potentialities for people with disabilities. The opportunities for communication and information acquisition are likely to be significantly expanded through online services, especially for people who are isolated by their disabilities... one of the major issues and applications of the new information technology is the potential for seamless communications and lifestyles for people with all sorts of disabilities...For people with disabilities, the degree to which they can participate in the new information age depends upon the degree to which the information age makes itself compatible with their needs. History has shown that the presentation of information has not shown much consideration for the needs of people with disabilities...the sense of companionship achieved through...private chat modes and the more public conferencing modes cannot be overemphasized..."23

From personal experience with a hearing impairment, one of the authors can readily recognize the advantages of a real-time digital reference service for persons with this particular disability. A profound hearing loss impeded his ability to perform a face to 
face reference interview, but his involvement with real-time digital reference allowed him to continue to share the reference workload. Thankfully, his situation has improved with surgery and he now enjoys the ability to participate in all modes of reference with confidence. Real time digital reference offers a tremendous alternative to regular users of TDD services.

On the DIG_REF listserv, there is a posting that will change anyone's view of the value of real-time digital reference. Lise Dyckman, Library Director of the California Institute of Integral Studies, tells the story of a patron with MS who was taking online courses and using a real-time digital reference service. ${ }^{24}$ This anecdote lends additional credence to the use of real-time digital technology to extend the reach of reference services, and should give its readers additional ideas of how to market the service to people whose lives will benefit from it. Librarians need to keep in mind that there are services available for the disabled to gain Internet access. Libraries only need to complete the connection for them.

In addition to physical disabilities, real-time digital reference can provide a breakthrough for those with anxiety, emotional or personality disorders. There are situations where shyness or self-consciousness can prevent a patron from using traditional reference service. Many veterans of real-time digital reference service have noticed that there are some patrons that will use the service from within the library in lieu of approaching the reference librarian in person. 


\section{OPPORTUNITIES IN THE ACADEMIC LIBRARY SETTING}

In the academic library setting, there are a number of occasions when the normal routines of patrons disrupt their access to the reference librarian. These disruptions can be viewed as opportunities for the expansion of reference services.

\section{The Needs of Travelers}

Faculty may be required to travel for conferences or testimony, or students may be required to travel for sporting events. As a result, they may be in a travel status for extended periods of time. In these cases, as well as others, there is a compelling need for real-time digital reference service in conjunction with digital resource use. Satisfying these needs in real-time can have a profound effect on quality of work or study.

\section{Distance Learning}

When an educational institution opts to expand their product via distance learning, it is imperative that provision of library services to the students is considered. Once again, real-time digital reference is the optimal solution for providing instruction in the use of digital resources because the user can see the librarians' information seeking behavior. Powell and Bradigan asked an important question about e-mail reference that can also be asked of real-time digital reference: "Should distance education students be 'penalized' because of choosing to take advantage of this new way to attend classes,

though they may pay the same tuition as on-campus students?"25 


\section{Support to Remote Research Facilities}

At universities like Carnegie Mellon, there are remote research facilities that might be well served by real-time digital reference. Carnegie Mellon's remote facilities include the Driver Training and Safety Institute an hour away, Carnegie Mellon's West Coast Campus (located in the NASA Research Park at Moffett Field, California), and the Athens Institute of Technology in Greece. In addition, there are more than fifty research centers affiliated with Carnegie Mellon in the city of Pittsburgh but not at the Carnegie Mellon campus. Serving these affiliates is a problem that is common for universities in urban settings. An example outside of Carnegie Mellon is provided by Jana Ronan of the University of Florida, who recounts a chat with a graduate student who is temporarily located in Tennessee. ${ }^{26}$

\section{The Role of the Regional Resource}

A large academic library may be designated a regional resource and receive funding to assist all who approach them for service. Gray notes this in the conclusion of her article: "Large research libraries whose collections hold unique items that are of a broader interest to those outside the institution have global or regional responsibilities to serve outside users. Virtual reference services provide an excellent opportunity to

communicate with these users." ${ }^{27}$ Early experience with QuestionPoint at Carnegie 
Mellon illustrates this type of opportunity with the added bonus of QuestionPoint's ability to track question status.

\section{Limited Service to Alumni}

Alumni frequently contact Carnegie Mellon with their information needs. Although we're not legally permitted to use our own resources to help them, we can use real-time digital reference to introduce them to resources in their new surroundings and point them to publicly available resources.

\section{Service to Emeritus Faculty}

Emeritus faculty members often decide to stay active within the department, but sometimes find themselves mobility impaired or geographically removed from the campus. They can still contribute and collaborate with long-time colleagues by remaining within virtual reach of the library's resources.

\section{Bibliographic Instruction}

Another opportunity exists within the realm of instructional software like Blackboard or WebCT. Professors can easily include librarians as guest lecturers via the chat function of the software. It would be interesting to survey librarians to determine the extent to which this is being done. 


\section{Service to Branch Campuses}

Many academic libraries provide services to branch campuses. Although print collections may exist at the branch facility, the multiple campus institution will often negotiate access to digital resources for the entire system. Again, real-time digital reference service allows academic librarians to be where and when their patrons need them. Reference staff from the entire system can be involved with providing the service.

\section{Collaboration}

Involvement of reference staff from multiple institutions (including other types of libraries) allows for the sharing of hours and expertise. Real-time digital reference service provides a mechanism for this to occur. An example would be children's and young adult librarians from nearby public and school libraries using real-time digital technology to provide reference service to education majors who are focusing their studies on these age groups. Keep in mind that many academic institutions will have a sole education librarian (who may be assigned other disciplines as well) trying to provide reference on his or her own. In return, subject specialists at the academic institution can provide specialized real-time digital reference assistance to the harried public library reference staff. 


\section{OPPORTUNITIES IN THE SPECIAL LIBRARY SETTING}

The special library setting can provide opportunities that echo those already discussed, but there are also opportunities that might be considered unique to this setting.

\section{Support for Branch Offices}

One opportunity that exists in the special library setting is reference support for small branch offices. Many special libraries that are part of for-profit companies remain hampered by licensing issues with publishers of digital resources. In a recent e-mail discussion with Denise Callihan of PPG Industries, the authors were given at least one solution that publishers could consider: the idea to price digital resources in a manner that charges the company based only on the number of employees who will want to make use of the resource. At the present time, many publishers charge amounts based on overall FTE. In addition, many publishers still try to charge corporate libraries for small branch offices (local area versus wide area pricing). Because of this, digital collection development in corporate libraries has been slower than what many corporate librarians had envisioned. Until these concerns are realized by publishers, only digital resources that are meant for a broader corporate audience will be purchased en masse. There are sales opportunities for publishers of scientific and technical information, if only publishers would make an effort to develop pricing that recognizes the logical level of use (perhaps FTE of the R\&D personnel) and get past their stringent views on what truly constitutes a second sale to a particular company. If this transpires, the authors envision a burgeoning need for real-time digital reference in corporate libraries - not to mention 
better bottom lines for the companies and the publishers. For now, real-time digital reference to branch offices remains limited by licensing issues.

\section{Librarianistic Teleswarms}

Years ago, one of the authors envisioned what he called "librarianistic teleswarms" - and yes, probably neither of the character strings in the phrase could be considered words at this point in time. What he meant was the idea that one large facility of a company (or research facility in this case) would provide backup for another of the company's large facilities in times of need. Special librarians are frequently pulled into projects or time sensitive research that will put a major stress on the quality of reference service at that particular facility. If their counterparts at another facility could swarm in to the rescue via real-time digital reference, then there you have it - "librarianistic teleswarms!" Somebody alert the folks at Merriam-Webster.

\section{The Needs of the Business Traveler}

Another reference need to consider is that of the business traveler. Employees that are traveling don't necessarily like to fall behind in their absorption of new information. And, when they return home, they may have family needs to look after. If their information flow is disrupted, catching up will unnecessarily cut into their quality of life. It would logically follow that librarians should be able to provide reference assistance in real time. It can be very inefficient to attempt a high level of assistance without features 
like cobrowsing or page pushing. Even the use of simple chat software is a better way to pass along a URL or a search strategy than the use of a telephone.

\section{OPPORTUNITIES IN THE SCHOOL LIBRARY SETTING}

\section{The Needs of Teachers and Administrators}

In Pennsylvania, there are support facilities for teachers, administrators, and librarians called Intermediate Units that are located throughout the state. Intermediate Units provide, among many other things, reference service to the school workforce. There's usually a geographic barrier challenging the support that the Intermediate Units can provide. The rapid shift to digital resources offers an opportunity for enhancements to the reference service that is being provided.

\section{The Traveling Librarian}

Many school librarians find themselves in situations where they must provide support to students at more than one school. These traveling librarian assignments afford a great opportunity for school librarians to employ real-time digital reference service. Just because the librarian is not present at a particular school on any given day does not mean that his or her reference skills have to be absent from that school. 


\section{CONCLUSION}

The authors hope that this article promotes the use of real-time digital reference services in all types of libraries. Acting on opportunities to provide these services with the hope of improving the quality of life of users and extending reference services to previously under-served populations will help to keep libraries fulfilling their educational and informational missions. If the reader is inspired to adopt any of these ideas, the effort will have been successful. 


\section{NOTES AND REFERENCES}

1. A discussion on the first real-time digital reference service took place on the DIG_REF listserv in August of 2002. Three postings that discuss the earliest known service of this type are contributed by Susan Ware, Lise Dyckman and Sam Stormont. These postings are available from the World Wide Web @ http://groups.yahoo.com/group/dig_ref/message/5853, http://groups.yahoo.com/group/dig_ref/message/5856, and http://groups.yahoo.com/group/dig_ref/message/5859.

2. R. David Lankes and Pauline Shostack, "The Necessity of Real-Time: Fact and Fiction in Digital Reference Systems," Reference \& User Services Quarterly 41, no. 4 (2002): $350-5$.

3. Steve McKinzie and Jonathan D. Lauer, "Virtual Reference: Overrated, Inflated and Not Even Real," The Charleston Advisor 4 no. 2 (2002): available from the World WideWeb@http://www.charlestonco.com/features.cfm?id=112\&type=ed.

4. McKinzie and Lauer.

5. McKinzie and Lauer.

6. Nancy O'Neill, posting to the DIG_REF listserv: available from the World Wide Web @ http://groups.yahoo.com/group/dig_ref/message/6246.

7. Roy Tennant, “Of Human and Humane Assistance,” Library Journal 124, no. 11 (1999): 30. 
8. Carol Tenopir, "Virtual Reference Services in a Real World," Library Journal 126, no. 12 (2001): $38-40$.

9. Don Leslie, "Industry Experts Gather to Map Future of Libraries," available from the World Wide Web @ http://www.3m.com/market/security/library/archives/pts/vision2008.jhtml.

10. Eleanor Sathan, "Can a Small Library Provide 24/7 Reference Service?" available from the World Wide Web @ http://www.vrd.org/conferences/VRD2002/proceedings/sathan.shtml.

11. Edana M. Cichanowicz, "Sunday Night Live! - An Experiment in Real Time Reference Chat - on a Shoestring Budget," The Charleston Advisor 2 no. 4 (2001): available from the World Wide Web @ http://charlestonco.com/features.cfm?id=59\&type=fr.

12. "The Washington Virtual Reference Project Overview" is available from the World Wide Web @ http://wlo.statelib.wa.gov/services/vrs/aboutvrs.cfm.

13. Melinda Patterson Grenier, "E-Branch Library Machines Help to Bridge Digital Divide," available from the World Wide Web @ http://www.digitaldividenetwork.org/content/news/index.cfm?key=413.

14. Jennifer Mathies, "Library Kiosks to Get Virtual Reference," posting to the PubLib listserv available from the World Wide Web @ http://sunsite.berkeley.edu/PubLib/archive/0201/0226.html.

15. Paula Musich, "A Futuristic Library," eWeek (2003): available from the World WideWeb @ http://www.eweek.com/article2/0,3959,508960,00.asp. 
16. Leila Fujimori, "Libraries Propose Public Internet Kiosks: the Terminals Would be Fully Equipped and Serve Areas with Little Access to State Libraries," Honolulu Star-Bulletin (Tuesday, September 26, 2000): available from the World Wide Web @ http://starbulletin.com/2000/09/26/news/story12.html.

17. "Brevard Library Foundation - Future Projects," available from the World WideWeb @ http://www.brevardlibraryfoundation.org/future.html.

18. Ronald R. Heezen, "Nebraska Information Technology Commission, Community Technology Fund 2002, Application Form, Project Title: Connect IT Omaha," available from the World Wide Web @ http://nitc.nol.org/cc/grants/2002/applications/ctf50connectomaha.pdf.

19. "Strengthening Neighborhoods," In States \& Communities Building the Future from the Ground Up, available from the World Wide Web @ http://www.benton.org/Library/Stake/states/states-full.html.

20. Andrea Kavanaugh, "The Use of the Internet for Civic Engagement: A View from Blacksburg, Virginia," a luncheon address to the Virginia Municipal League, October 21, 1996, available from the World Wide Web @ http://www.bev.net/about/research/reports/docs/VAMuniLeague.address.pdf.

21. Godavari Devendrappa Patil, "Computer Access and Utilization Patterns of Older People," (Warrensburg, MO: Central Missouri State University, 2002), abstract available from the World Wide Web@ http://wwwlib.umi.com/dissertations/fullcit/1407333.

22. "Seniors Get Pally on the Net," Southern Star (March 13, 2002), available from the LexisNexis ${ }^{\mathrm{TM}}$ Academic database. 
23. "Online Services for People With Disabilities in Australian Public Libraries. A Review of the Literature by Information and Telecommunications Needs Research (ITNR), Monash University,” (January, 2000): available from the World Wide Web @ http://www.infotech.monash.edu.au/itnr/reports/review1.pdf.

24. Lise Dyckman, posting to the DIG_REF listserv: available from the World Wide Web @ http://groups.yahoo.com/group/dig_ref/message/4799.

25. Carol A. Powell and Pamela S. Bradigan, "E-mail Reference Services: Characteristics and Effects on Overall Reference Services at an Academic Health Sciences Library," Reference \& User Services Quarterly 41, no. 2 (2001): 170-8.

26. Jana Ronan, "Chat Reference: an Exciting New Facet of Digital Reference Services," ARL no. 219 (2001): 4-6.

27. Suzanne M. Gray, "Virtual Reference Services: Directions and Agendas," Reference \& User Services Quarterly 39, no. 4 (2000): 365-75. 